\title{
Looking beyond English: Linguistic inquiry for English Language Learners
}

\author{
Daniel Ginsberg (CAL), Maya Honda (Wheelock College), and Wayne O’Neil (MIT)
}

0. Introduction. Honda and O'Neil (1993: 237) suggested that linguistic inquiry in the K-12 school curriculum would ideally "take advantage of the linguistic diversity of a class of students to examine cross-linguistic, crossdialectal, and cross-modular phenomena." Subsequently, Honda, O'Neil, and Pippin (2010: 186-187) found that "[c]omparing English to other languages is especially rewarding when students have another language at home, for it piques their interest in these languages. Students have even on occasion asked to create problem sets [for the class] on their own and have done so with the help of family members."

At the invitation of Daniel Ginsberg, the three of us pursued this idea further, exploring the potential of linguistic inquiry in a linguistically diverse class of high school students - all native speakers of a language other than English.

- Our questions: Is there a role for linguistic inquiry in a class of high school ELLs? In particular, can the analysis of students' home languages interest and engage them in critical inquiry?

Based on our 2008-2009 pilot project, we believe the answer to these questions is 'Yes'. In this paper, we present evidence to support this conclusion.

1. Background: The setting and the students. The pilot project took place at a public high school in Greater Boston where Ginsberg was then an ESL teacher. Ginsberg initiated this project because he was seeking to supplement the curriculum of his high-intermediate ESL class with critical inquiry activities.

Ginsberg's high-intermediate ESL class had about 10 students, with the exact number changing as students' English proficiency was reassessed and their course assignments were modified. The class included speakers of Cantonese, French, Haitian Creole, Hindi, Mandarin Chinese, Punjabi, Spanish, and Tibetan - a small fraction of the 67 languages spoken by students in the school district.

2. The curriculum-in-process: An idea and its execution. The curriculum that we developed emphasized collaborative, cross-linguistic analysis of the students' languages, including, of course, English. Although English was the language of the classroom and an object of inquiry, our primary goal was to look beyond English to engage students in critical inquiry about their home languages. In ten class meetings across the year, we covered four topics: NP pluralization, language acquisition, writing systems, and translation. Beyond NP pluralization and language acquisition, for which Honda and O'Neil had existing materials and activities, the curriculum evolved in response to what the students found interesting and curious about their own and each other's home languages.

2.1 NP pluralization. We began by inviting students to become linguists by working through a problem set on the morphophonology of NP plural formation in Armenian (Honda and O'Neil 2008). As they worked through the problem set, they were introduced to linguistics terms and concepts ('singular', 'plural', 'noun', 'suffix', 'syllable', 'consonant', 'vowel'), as well as terms and concepts of scientific inquiry ('data', 'hypothesis', 'counterexample').

We then examined NP pluralization in the students' languages. Students were asked to translate pairs of singular and plural NPs from English into their languages; to compare and contrast the pairs; then on the basis of their analysis, to formulate a hypothesis in explanation of the data. Their analyses required that more linguistic terms and concepts be introduced ('definite article', 'indefinite article', 'classifier'), and that previously introduced terms be reviewed.

This work culminated with students' presenting on NP pluralization in their languages. They began with general information about the language and its speakers (using Ethnologue as a resource) and then led the class to an understanding of NP pluralization by giving examples of singular and plural NPs; by asking the audience to identify suffixes, changes in words, or other differences; and then by explaining their hypothesized rules.

The students' accounts were, for the most part, descriptive. The Tibetan speaker, for example, noted that his language has singular and plural morphemes and that in informal speech they could be dropped, but only in [+definite] NPs. And despite their shared language background, the four Chinese students, educated in Mandarin Chinese and native speakers of Cantonese, came to different analyses of NP pluralization - just as real linguists often do. For example, one student used $y i$ - 'a, one' as the quantifier for singular NPs and correctly used the plural classifier $x i e$ 些 preceded by $y i$, but only for [-animate] plural NPs. For [+animate] plural NPs, he chose a 'massifier', the collective qún 群 ‘flock, group, etc.' preceded by $y i$. The fourth student went further, distinguishing [-definite] yi 'a, one' from [+definite] zhè 这 'the, this'. We found this challenging to make sense of and, of course, interesting.

And so the presentations went for the other languages, with students offering questions and comments throughout. For example, the Spanish speaker observed that in her language NP plurality was indicated in both the determiner and the noun: "You have to add both sides $-s$." She and other students noticed that the $-s$ suffix marks plurals in 
Ginsberg, et al., Looking beyond English

English, French, and Spanish. This may be why she raised her hand at the end of the Hindi speaker's presentation and said, "I have a question. Do you have $-s$ ?" To which, he replied, "No, my language is different.

2.2 Language acquisition. Students prepared for a discussion of language acquisition by reading the relevant section of Daniels 1983. We began with the question, How did you learn your native language? Students' responses ranged from the view that they were taught the language to the idea that they just "got" it.

In order to have them investigate children's native language development, we told the students that they would collect data from a video and observe young children interacting with their family. Before watching the video, they were asked to predict how they would characterize the language of children of different ages based on their prior knowledge and experience. Students then tested their predictions against data collected from a video segment (Stiles \& Montagnon 1991) that highlights the everyday language use of the Berrigan family, all of them deaf and speakers of ASL. The Berrigan children, Kevin, Di, and Crystal, are 11 months old, 3 years old, and 5 years old, respectively.

Knowing only their ages and not their native language, students, following intuitions based in a different modality, made quite accurate predictions:

- $\quad$ Kevin: He will try to talk; he will learn some words - mommy, daddy, toy; babbling funny sounds; no speaking.

- Di: She will know words and say them; she will know a lot of words; she might mispronounce words; no sentences or only some simple sentences.

- $\quad$ Crystal: She'll talk perfectly; she'll start to write.

Students then watched the video and recorded their observations. Afterwards, they discussed whether or not the data supported their predictions and concluded that they did.

2.3 Writing systems. As students analyzed NP pluralization in their languages, they noted with interest the writing systems being used. Students expressed fascination with and pride in the non-alphabetic systems on display. For example, the Tibetan speaker took great care in employing three alphasyllabic scripts during his presentation. So we decided to follow students' interests and look further into this topic.

To prepare for the discussion of writing systems, students were asked two questions: Do all languages have a writing system? How was writing first invented? Every student answered 'yes' to the first question. The class then read and listened to Daniels 2005, after which they realized that they were wrong about the first question.

2.3.1 System types. The students then turned to other questions: In your language, what's the smallest written symbol that you can read? What's the smallest written symbol that means something? How many symbols does it take to spell /ma/? For the last question, there were these answers: two symbols for the Latin ("English") alphabet; one for Tibetan; one and a half for Hindi; three different symbols for Chinese.

Next, students were introduced to three types of writing systems:

1. those that have one symbol for each unit of meaning

2. those that have one symbol for each unit of sound

3. mixed systems that have symbols for both units of meaning and units of sound.

Students were asked to identify what type of writing system is used to represent their language and to give examples in support of their answer. The discussion that followed was quite rich because of the different writing systems of students' home languages: Mandarin Chinese and Cantonese represented type 1 systems that have one symbol for each unit of meaning; French, Haitian Creole, Spanish, Tibetan and Punjabi represented type 2 systems that have (more or less) one symbol for each unit of sound. When asked, Do you ever use a symbol for a whole word? a speaker of Haitian Creole and French replied, "Numbers"; this illustrated the mixed nature of even type 2 systems.

2.3.2 Moving between systems. We next examined the Cherokee syllabary and its usefulness in representing students' home languages. This activity allowed us to introduce the class to an indigenous language of North America and to the syllabary that Chief Sequoyah created for the language. The class was given a handout with the syllabary and asked, Could you use the Cherokee syllabary to write your language? Why or why not? Given the syllable structure of the languages in the class, this task varied from being relatively easy to difficult to impossible.

It was interesting to observe students grappling with this problem set. Many of them were confused about the phonetic conventions of the Cherokee syllabary, for example, using the symbol for the Cherokee syllable /we/ for English we, not understanding that the two are pronounced differently. In previous classes, it was clear that students believed that the spoken and written forms of their home language were one and the same thing (a view that supported their misconception that all languages have a writing system). For example, a Haitian Creole speaker 
Ginsberg, et al., Looking beyond English

wrote that "Creol is very easy because you just write the word that your hear." Working with the Cherokee syllabary introduced some cognitive dissonance about the presumed relationships between sounds and symbols as well as between spoken and written language.

2.4 Translation. The final topic of our pilot curriculum was translation - a relevant topic for these bilingual students. We began with the question, What is translation? Everyone agreed with the student who said, "Meaning from one language to another."

Students were then given the Omniglot entry for their home language, which gave a description of the language and its speakers, the writing system for the language, and Article 1 of the UN Universal Declaration of Human Rights written in the language - their assignment being to translate Article 1 into English.

This was a very engaging activity that captivated students' attention. In fact, two students, who were not in the class but were studying in the classroom, jumped right in. Working with a language partner or with one of us if they were the only speaker of their language, students were quite focused in their work. They thought a lot about what words meant and what words to use for their translation, only occasionally using paper and electronic dictionaries.

While a few students said the translation exercise was easy, most found it difficult for a variety of reasons. Some students discovered that a translation dictionary was not always a useful tool, as when a Spanish speaker was puzzled by the Spanish word dotado. "What's that?" she asked. When she looked up the word in a Spanish-English dictionary, she found that it meant 'endowed', an English word that she also did not know. Despite her lack of understanding, she used endowed in her translation. Another student initially felt he could not do the translation because of his inability to read Haitian Creole well, as the following conversation he had with one of us indicates: "I can't pick it up and do it," he said. "But what if [your partner] reads it to you?" "Then I can - sure." "That's because the language is in your head, not on the paper." "That's what I told him!" he said, pointing to his partner. So he worked on the exercise orally and his partner wrote their translation down. When students presented their translations to the class, this student declared, "Ours is the best!"

The students made posters of their translations, presented them to the class, and displayed them in the classroom. Here are a few of the translations:

- All that human are born free and equals in dignity and rights and they are endowed with reason and conscience. They to be support each other. (translated from Spanish)

- All humans are free and they have own right and they are born equal. They have brain or knowledge to recognize bad or good things. They are live like brother and they do nice behavior to each other. (translated from Hindi)

- $\quad$ Everyone is born free, equal. We have the reason and conscience. And we need to act with one another like brothers. (translated from Haitian Creole)

When asked, Why are the translations different? students attributed the differences to "different people" or "different word or words." As can be seen above, some translators made more nuanced word choices than others.

\section{Findings.}

3.1 What students learned. Before the final class, students were asked to write about what they had learned about language and what questions they still had. Some of their responses to this informal survey were about specific topics that we covered; some were more global comments about language. Here is a representative selection of responses to this informal survey:

- Suffix - A letter that we add at the end of a word like s, x. Plural - A word that's not singular and means more than one.

- In English plural is s or es but in Hindi a lot of the like (yan) or (ae).

- Language was not only that speak but they also have sign language. We watched a movie about a family using sign language and parent and children all use that sign to communicated each other.

- Children learn language. For first is pronounce, then learn syllable. Next they can speak. After that they can read and write.

- $\quad$ On our linguistics class we talk about the different language and their similary part and different part. We discussed about that by looking on the plural and singular of the words...

- We learn how lots language related to each other and they have some similary writing and reading also way of sentence goes that tell us language are relate to each other as a human evolution. They are connect each other. 
Ginsberg, et al., Looking beyond English

Students also had questions, such as:

- Is it the same sign language between Chinese and America?

- Do you think it is better know more than 10 language?

- How many languages are there?

- What is common to all languages?

- How many languages can you speak?

3.2 What we learned. In this pilot project, our primary goal was to look beyond English to engage ELLs in critical inquiry about their home languages. Here are some of the things that we learned from this work:

- Students have different levels of education in their languages. Some are highly literate in their home language, while others are barely literate, if at all. Many come from cultures where different languages are used in home and school, such as Haitian Creole / French or Cantonese / Mandarin. Also, depending on the education they received in their home country and the length of time they have been in the US, some ELLs may be more comfortable in English than in any other language. Class activities and assignments must accommodate this range of backgrounds.

- $\quad$ Each of the four topics that we covered took a lot of preparation. We needed to know enough about the spoken and written forms of the students' languages to guide and support their work. Among the three of us linguists, we already knew a lot, but we certainly needed to learn more before we taught the class.

- At the same time, one of the greatest affective benefits of using students' home languages as classroom content is that it authentically puts students in the role of expert. Often, students are shy about discussing academic content in English, but as we observed, they may be motivated by an adult who says, "I don't know how your language works; please teach me."

- Despite the fact that students struggled with oral and written English, this did not prevent them from enthusiastically investigating the oral and written forms of their home languages. Their languages were a resource, not a hindrance.

4. Significance. In this time of English-only education, students' home languages are rejected in schools. But we believe that this pilot study indicates an important role that their languages can play in the ESL classroom. Although the time spent on linguistic inquiry in this class of ELLs was very limited, students were clearly drawn into exploring their own language as well as those of their classmates, learning facts and concepts about language and about inquiry. Thus, based on our observations and students' oral and written work, we conclude that:

- $\quad$ Examining the structures of the spoken and written languages represented in the classroom captures students' interest and engages them in critical inquiry about the nature of linguistic knowledge and about their beliefs about language.

- The cross-linguistic analysis of students' languages validates their languages in the school context, defining them as a rich resource worthy of study, rather than as a hindrance to education.

There is a role for both linguistic inquiry and home languages in the ESL classroom. Indeed, we believe that learning about the many languages that students bring to school should have a place in the general education of all students. We hope that this pilot project will lead to more work of this sort.

\section{References.}

Daniels, Harvey A. 1983. Famous last words: The American language crisis reconsidered (Chapter 4: Nine ideas about language, [Idea] 1. Children learn their native language swiftly, efficiently, and largely without instruction). Carbondale and Edwardsville IL: Southern Illinois University Press.

Daniels, Peter T. 2005. Where did writing come from? The 5-minute linguist. College of Charleston and the National Museum of Language. Online: http://spinner.cofc.edu/linguist/archives/2005/06/where did writi.html?referrer=webcluster\&

Ethnologue: The languages of the world. 2009. Online: http://www.ethnologue.com/web.asp

Honda, Maya \& Wayne O’Neil. 1993. Triggering science-forming capacity through linguistic inquiry. The view from Building 20, ed. by Kenneth Hale and Samuel Jay Keyser, 229-255. Cambridge MA: MIT Press.

Honda, Maya \& Wayne O’Neil. 2008. Thinking linguistically. Malden MA and Oxford UK: Blackwell.

Honda, Maya, Wayne O’Neil, \& David Pippin. 2010. On promoting linguistics literacy: Bringing language science to the English classroom. Linguistics at school, ed. by Kristin Denham and Anne Lobeck, 175-188. Cambridge UK: Cambridge University Press.

Omniglot: Writing systems \& languages of the world. 1998-2009. Online: http://www .omniglot.com/writing/definition.htm Stiles, Geoff Haines, \& Peter Montagnon (producers). 1991. Childhood: Love's labors [video]. New York: Ambrose Video Publishing. 